\title{
ANÁLISE DA TEORIA DA ENTROPIA UTILIZANDO DADOS PLUVIOMÉTRICOS NO ESTADO DA PARAÍBA
}

\author{
${ }^{1}$ Izaias Romário Soares do Nascimento, ${ }^{2}$ Péricles de Farias Borges, ${ }^{1}$ Edileide Natália da Silva \\ Rodrigues, ${ }^{1}$ Felipe Marinho Coutinho de Souza, ${ }^{1}$ Paulo Henrique de Almeida Cartaxo, ${ }^{2}$ Lázaro de \\ Souto Araújo, 3João Paulo de Oliveira Santos \\ 1Universidade Federal da Paraíba - Graduação em Agronomia; ${ }^{2}$ Universidade Federal da Paraíba - Professor Doutor / \\ Departamento de Ciências Fundamentais e Sociais; ${ }^{3}$ Universidade Federal da Paraíba - Doutorando do Programa de \\ Pós-Graduação em Agronomia.
}

RESUMO: O estudo da precipitação é de grande importância, visto a importância dessa variável no ciclo hidrológico e em diversas atividades humanas. A entropia como teoria da incerteza, permite o estudo da variabilidade da precipitação. O objetivo do presente trabalho foi avaliar a variabilidade da precipitação no estado da Paraíba por meio da teoria da entropia de Shannon. Foram utilizados dados diários de precipitação de um período de 11 anos, de 51 postos pluviométricos distribuídos na Paraíba, aos quais foi aplicada a teoria da entropia para cálculo da entropia anual e após isso a construção de mapas de entropia, precipitação e número de dias com chuvas para o estado da Paraíba e suas mesorregiões. As maiores precipitações foram observadas na Mata paraibana com valores entre 900 e 1600 mm anuais, no Agreste há uma amplitude maior da precipitação, onde os valores variaram entre 450 a $1150 \mathrm{~mm}$, no Sertão tem-se pouca variação espacial. O número de dia com chuvas tem pouca variação no estado, sendo que em parte do Agreste e na Mata paraibana tem-se maiores valores. A entropia teve comportamento semelhante a precipitação e ao número de dias com chuvas. A variabilidade espacial da precipitação é bastante acentuada na Paraíba, sendo menor no Sertão do estado, exceto para a microrregião de Teixeira; a variabilidade temporal da precipitação é maior em localidades com menor número de dias chuvosos e menor precipitação anual, dependendo não unicamente do total acumulado.

Palavras-chave: Recursos Hídricos; Teoria de Shannon; Variabilidade da Precipitação.

\section{ANALYSIS OF THE ENTROPY THEORY USING PLUVIOMETRIC DATA IN THE STATE OF PARAÍBA}

ABSTRACT: The study of precipitation is of great importance, considering the importance of this variable in the hydrological cycle and in several human activities. The entropy as uncertainty theory allows the study of precipitation variability. The objective of the present study was to evaluate the precipitation variability in the state 
of Paraíba through the Shannon entropy theory. We used daily precipitation data from a period of 11 years, from 51 pluviometric stations distributed in Paraíba, to which the entropy theory was applied to calculate the annual entropy and after that the construction of entropy maps, precipitation and number of days with rainfall for the state of Paraíba and its mesoregions. The highest rainfall was observed in the Paraiba Forest with values between 900 and $1600 \mathrm{~mm}$ annually, in the Agreste there is a greater amplitude of the precipitation, where the values varied between 450 to 1150 $\mathrm{mm}$, in the Sertão there is little spatial variation. The number of days with rainfall has little variation in the state, being that in part of the Agreste and in the Paraíba Mata has higher values. The entropy had similar behavior to precipitation and to the number of rainy days. The spatial variability of the precipitation is quite pronounced in Paraíba, being smaller in the Sertão of the state, except for the micro-region of Teixeira; the temporal variability of precipitation is higher in locations with fewer rainy days and less annual precipitation, depending not only on the accumulated total.

Keywords: Water resources; Shannon's theory; Precipitation variability.

\section{INTRODUÇÃO}

O estado da Paraíba, situado entre os paralelos 6 e $8^{\circ}$ ao sul de latitude e entre os meridianos 34 e $39^{\circ}$ de longitude oeste, é dividido em quatro mesorregiões, ocupando uma área de aproximadamente $56.340,9 \mathrm{~km}^{2}$. A precipitação no estado sofre influência de vários sistemas meteorológicos, como a Zona de Convergência Intertropical (ZCIT), sistemas frontais, brisas terrestres e marítimas, bandas de nebulosidade, linhas de instabilidade, etc. (GOMES et al., 2015), como também de efeitos orográficos locais (MACEDO et al., 2010; ALVES et al., 2015).

A precipitação influencia em diversas atividades humanas, tais como a agricultura, a pecuária, a pesca e principalmente o abastecimento de água para consumo humano, de forma que é uma das variáveis meteorológicas mais importantes do ciclo hidrológico (SILVA et al., 2012). Essa variável possui importância direta nas condições ambientais, pois além de agir diretamente sobre o balanço hídrico no solo, tem grande influência em outras variáveis meteorológicas, como temperatura, umidade relativa do ar e a radiação solar (MEDEIROS et al., 2015).

Conforme Silva et al. (2003), a precipitação média na maior parte do estado da Paraíba é inferior a $800 \mathrm{~mm}$ anuais, no entanto, no litoral os totais anuais podem superar os $1800 \mathrm{~mm}$. Nesse sentido, nota-se que os índices pluviométricos são muito variados espacialmente, como também temporalmente, sendo assim imprescindível o monitoramento do comportamento da precipitação. 
Diferentes metodologias têm sido utilizadas no intuito de analisar a variabilidade da precipitação, e a entropia tem se mostrado eficiente conforme alguns trabalhos, como Medeiros et al. (2015), que avaliaram a sua aplicação no estudo da precipitação em Teresina - PI, concluindo que a entropia é mais eficiente que o desvio-padrão na análise de dados em torno da média.

O conceito de entropia utilizado primeiramente na física termodinâmica por Clausius em 1850, foi mais recentemente utilizado por Shannon (1948), na análise econômica e em solução de problemas relacionados com a teoria de codificação e transmissão de dados, teoria da informação. A teoria define a incerteza como entropia, a qual leva em conta todos os tipos de informações disponíveis e representa a distribuição da probabilidade da variável em questão.

O conhecimento da entropia vem sendo utilizado em diversas áreas do conhecimento, como na medicina (FARCHE et al., 2017), na ecologia (JULES, 2017), biologia (FERNANDES et al, 2003), climatologia (CHEN, 2008), dentre outras. Especificamente na meteorologia o conceito já foi utilizado por Santana (2018), no estudo da variabilidade espacial e temporal da velocidade do vento no Nordeste brasileiro. Nesse sentido, tomando como base as potencialidades de uso dessa técnica, o presente trabalho objetivou avaliar a variabilidade espacial e temporal da precipitação no estado da Paraíba e suas mesorregiões por meio da teoria da entropia de Shannon.

\section{MATERIAL E MÉTODOS}

O estado da Paraíba está situado no Nordeste brasileiro, predominantemente na região semiárida, o Estado está dividido em quatro mesorregiões: Sertão, Borborema, Agreste e Mata Paraibana (Rodriguez, 2002). O clima do estado, conforme classificação de Köppen, é dividido em As (Tropical com chuvas de inverno), que predomina na Mata Paraibana, Sertão e em parte do Agreste, BSh (Árido do tipo Estepário, seco e quente), predomina em toda a Borborema e parte do Agreste e Sertão, e em algumas partes da Mata Paraibana tem-se os tipos Aw (Tropical com chuvas de verão) e Am (Tropical do tipo monções) (FRANCISCO et al., 2015).

Os dados utilizados no presente trabalho são diários, referentes a um período de 11 anos, 2005 a 2015, de 51 postos pluviométricos distribuídos em todo o estado 
(Figura 1), obtidos no Departamento de Ciências Atmosféricas da Universidade Federal de Campina Grande (DCA/UFCG). Os postos foram selecionados conforme a melhor distribuição em todo o estado e dados contínuos e sem falhas.

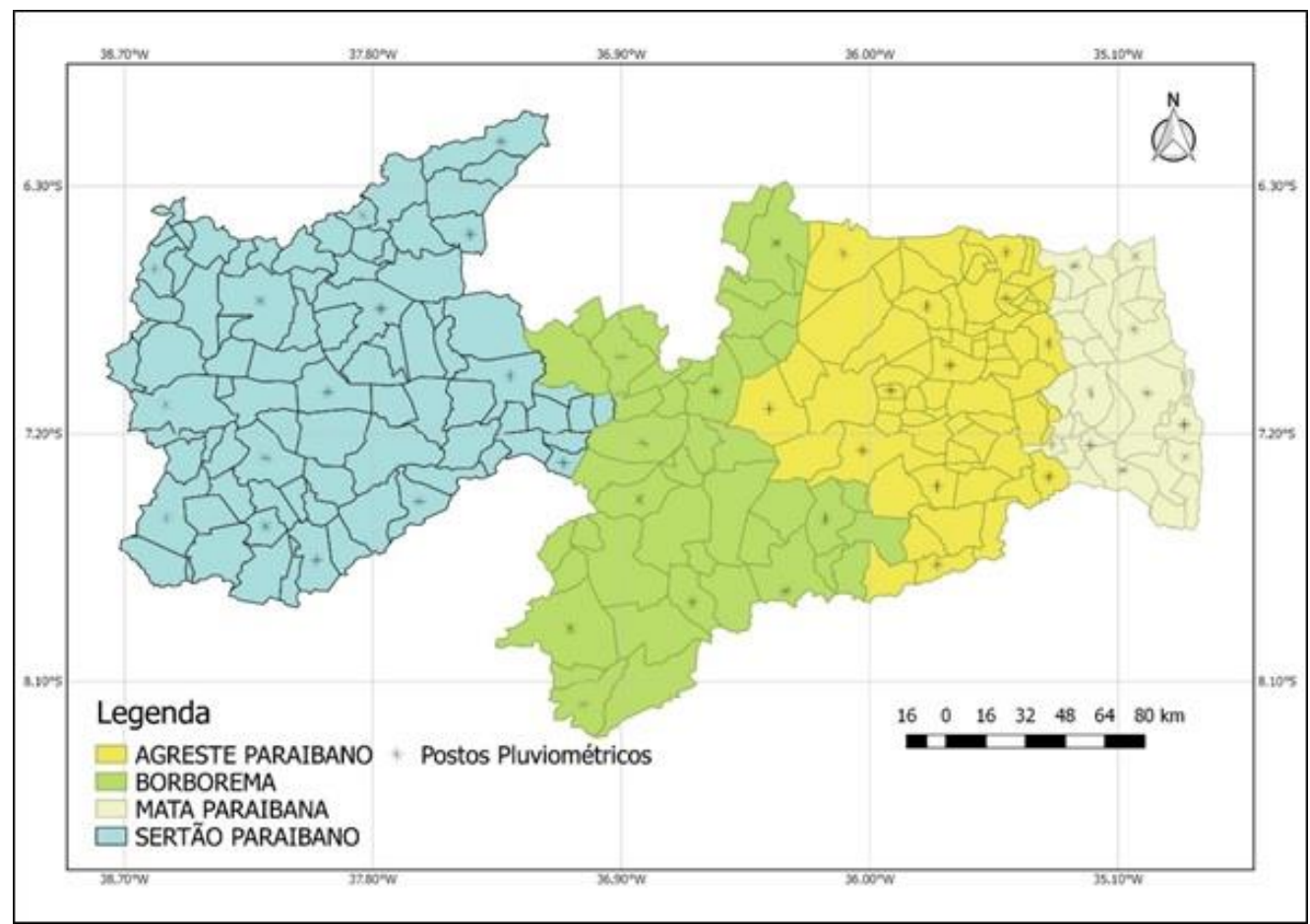

Figura 1. Distribuição geográfica dos postos pluviométricos nas mesorregiões do Estado da Paraíba.

Para o cálculo da entropia foi utilizada a equação proposta por Shannon (1948) (Eq. 1), que conforme a mesma a entropia é considerada a estimativa da incerteza da ocorrência de um determinado evento num processo aleatório (SILVA et al., 2003), a unidade da entropia pode ser em bits, napiers ou hartley, sendo que para cada uma deve ser usada uma base logarítmica, sendo essas 2, base neperiana e 10, respectivamente, no caso do presente trabalho foi utilizada a base 2 para a unidade em bits.

$$
H=-k \sum_{i=1}^{n} p i \log _{2} p i
$$

Onde: $\mathrm{H}$ - entropia, bits; pi - probabilidade da enésima variável aleatória discreta, adimensional; $\mathrm{k}$ - constante positiva cujo valor depende da unidade, no caso de bist 
é igual a $1 ; \mathrm{n}$ - número possível de eventos da variável aleatória discreta, adimensional.

A frequência relativa $(\mathrm{Pi})$ no caso do presente trabalho é a probabilidade de ocorrência do total de precipitação no enésimo dia, representando a incerteza da ocorrência de precipitação no determinado dia, para cálculo do mesmo utiliza-se a eq. 2: $\mathrm{Pi}=\frac{\mathrm{ri}}{\mathrm{R}}$

Onde: ri - corresponde a precipitação pluvial no enésimo dia do ano, $\mathrm{mm}$; $\mathrm{R}$ expressa o somatório da precipitação na série analisada, $\mathrm{mm}$.

Substituindo a Eq. 2 na Eq. 1, têm-se a equação 3:

$H=-k \sum_{i=1}^{n} \frac{r i}{R} \log _{2}\left(\frac{r i}{R}\right)$

Como a série de dados avaliada é de um período de 11 anos, foram feitas as médias (Eq. 4) da entropia anual para todos os postos pluviométricos.

$\overline{\mathrm{H}}=\frac{1}{\mathrm{n}} \sum_{\mathrm{i}=1}^{\mathrm{n}} \mathrm{H}$

Onde: $\overline{\mathrm{H}}$ - entropia média, bits; $\mathrm{n}$ - número de anos da série avaliada; $\mathrm{H}$ - entropia anual, bits.

Para melhor apresentação dos resultados correspondentes as precipitações anuais, do número de dias com chuvas no ano e da entropia, foram elaborados mapas no SIG QGIS a partir da interpolação dos dados dos postos pluviométricos para todo - Estado e para as quatro mesorregiões (Sertão, Borborema, Agreste e Mata 
paraibana), por meio do algoritmo inverter a distância a uma potência. Foram realizadas também no QGIS, as curvas ligando os locais de mesma entropia (isoentropias), mesma precipitação (isoietas) e mesmo número de dias com chuvas.

\section{RESULTADOS}

Na Figura 2, estão apresentados a distribuição espacial no estado da Paraíba da precipitação média anual $(A)$, do número de dias com precipitação no ano $(B)$ e da entropia média anual (C). A precipitação (Figura 2A) é maior na Mata paraibana com valores entre 900 e 1600 mm anuais, no Agreste há uma amplitude maior da precipitação, onde os valores variaram entre 450 a $1150 \mathrm{~mm}$, mostrando que nessa mesorregião a variação espacial da precipitação é maior. O contrário do que ocorre no Agreste, ocorre no Sertão, sendo essa a mesorregião com menor variação espacial da precipitação, variando entre 700 e 940 mm. A mesorregião da Borborema é a que registra menores precipitações em todo o estado, os valores variam entre 400 e 700 $\mathrm{mm}$.

O número de dias chuvosos (Figura 2B), tem menor variação espacial no Estado, sendo que os valores das mesorregiões do Sertão, Borborema e parte do Agreste são semelhantes, variando, dessa forma, na maioria do estado, entre 45 e 60 dias, na Mata paraibana e em parte do Agreste é onde o número de dias chuvosos são maiores, variando entre 75 e 180 dias.

A entropia (Figura 2C), teve comportamento semelhante a precipitação e ao número de dias chuvosos, onde os maiores valores foram registrados na Mata paraibana e no Agreste, variando entre 5 e 6,5 bits nessas regiões, a partir do Agreste os valores começaram a diminuir em direção a Borborema, mesorregião com menores valores (4,1 a 5 bits). Pequena parte do Sertão registrou entropias com valores semelhantes ao Agreste e Mata paraibana, sendo a mesorregião em que a entropia também registrou menor variação espacial. 


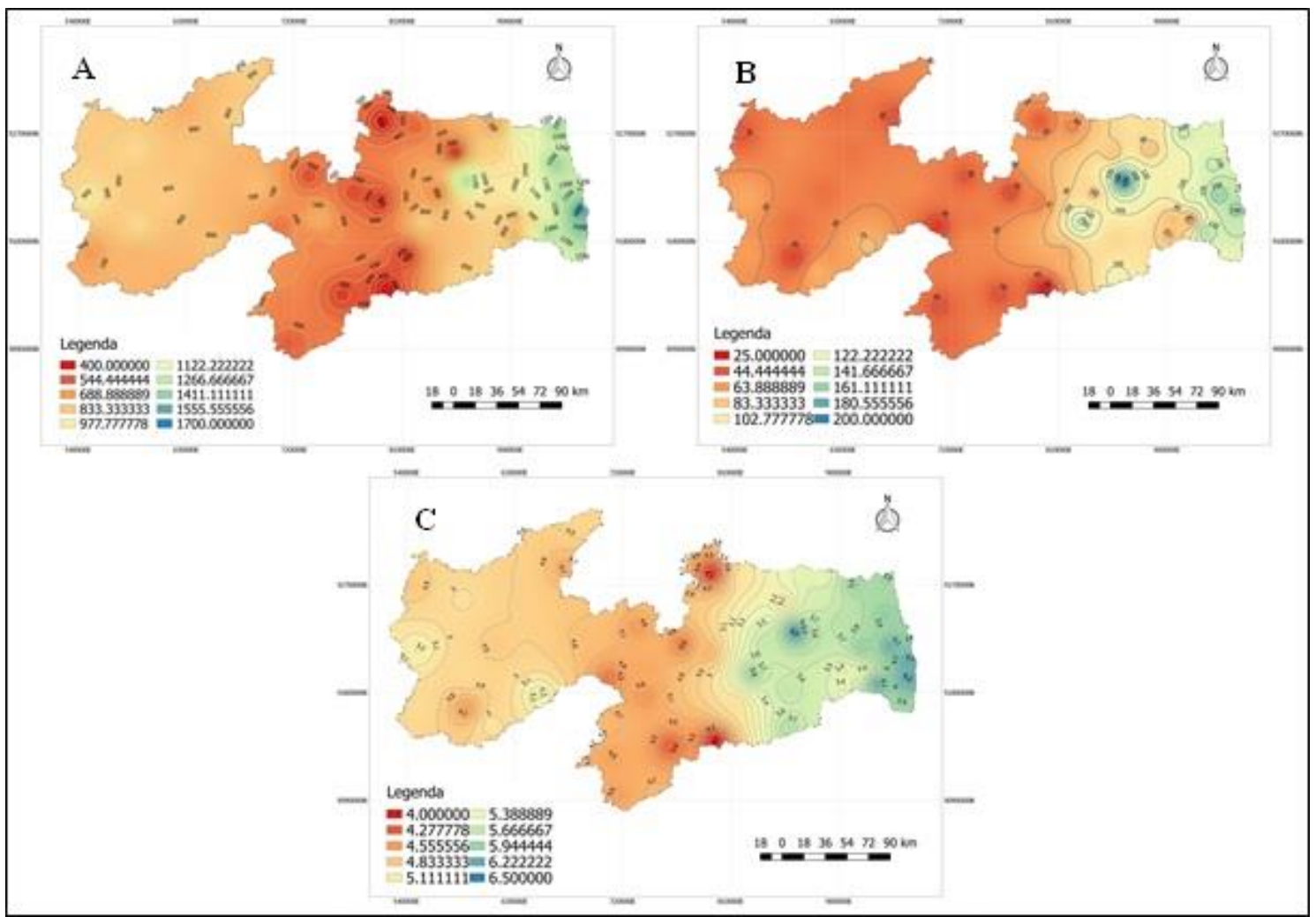

Figura 2. Mapa de distribuição e de isolinhas da precipitação média anual (A), do número de dias chuvosos $(B)$ e da entropia média anual $(\mathrm{C})$ no estado da Paraíba.

Conforme possível observar na Figura 3A, a precipitação na Mata paraibana é maior na microrregião de João Pessoa e os menores valores na microrregião de Sapé, as microrregiões de Litoral Norte e Litoral Sul apresentam valores intermediários. Assim como na precipitação, para o número de dias chuvosos (Figura 3B), a microrregião de Sapé foi a que apresentou menores valores e na de João Pessoa os maiores, sendo que as maiores precipitações foram registradas no município de João Pessoa (1680 mm) e o maior número de dias chuvosos no município de Santa Rita (160 dias). Para as microrregiões do Litoral Norte e Sul o número de dias chuvosos foi semelhante e com pouca variação, com valores entre 130 a 140 dias.

A entropia na mesorregião da Mata paraibana (Figura 3C), teve comportamento mais semelhante ao número de dias chuvosos (Figura 3B), no que se refere a variação espacial, onde a microrregião de João Pessoa também registrou os maiores valores e consequentemente menor variação temporal da precipitação. As microrregiões de Litoral Sul e Norte assim como para precipitação e número de dias chuvosos apresentaram valores intermediários de entropia e com pouca variação espacial $(5,9$ 
a 6 bits), assim como também a microrregião de Sapé foi a que apresentou menores valores de entropia e maior variação temporal da precipitação.

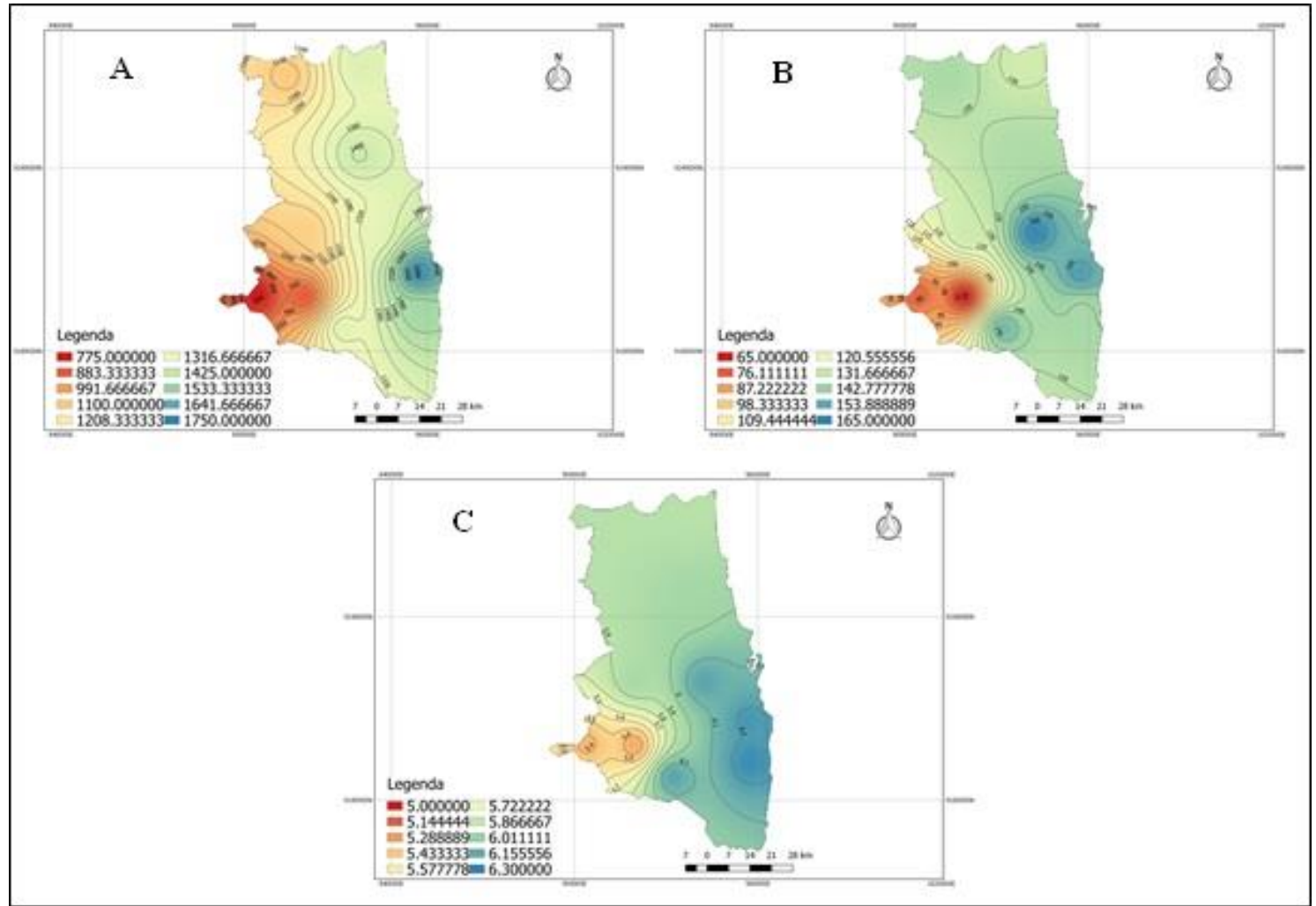

Figura 3. Mapa de distribuição e de isolinhas da precipitação média anual (A), do número de dias chuvosos (B) e da entropia média anual $(C)$ na mesorregião da Mata paraibana, Paraíba.

$\mathrm{Na}$ Figura 4, encontram-se a distribuição e as isolinhas da precipitação $(A)$, do número de dias chuvosos $(\mathrm{B})$ e da entropia $(\mathrm{C})$ para a mesorregião do Agreste paraibano, como possível observar nas microrregiões do Brejo e de Guarabira são registradas as maiores precipitações (Figura 4A), no Brejo os valores variam entre 800 e $1300 \mathrm{~mm}$. As microrregiões do Agreste de menor índice pluviométrico são o Curimataú Oriental e Ocidental, onde os valores variam entre 450 e 700 mm anuais. 


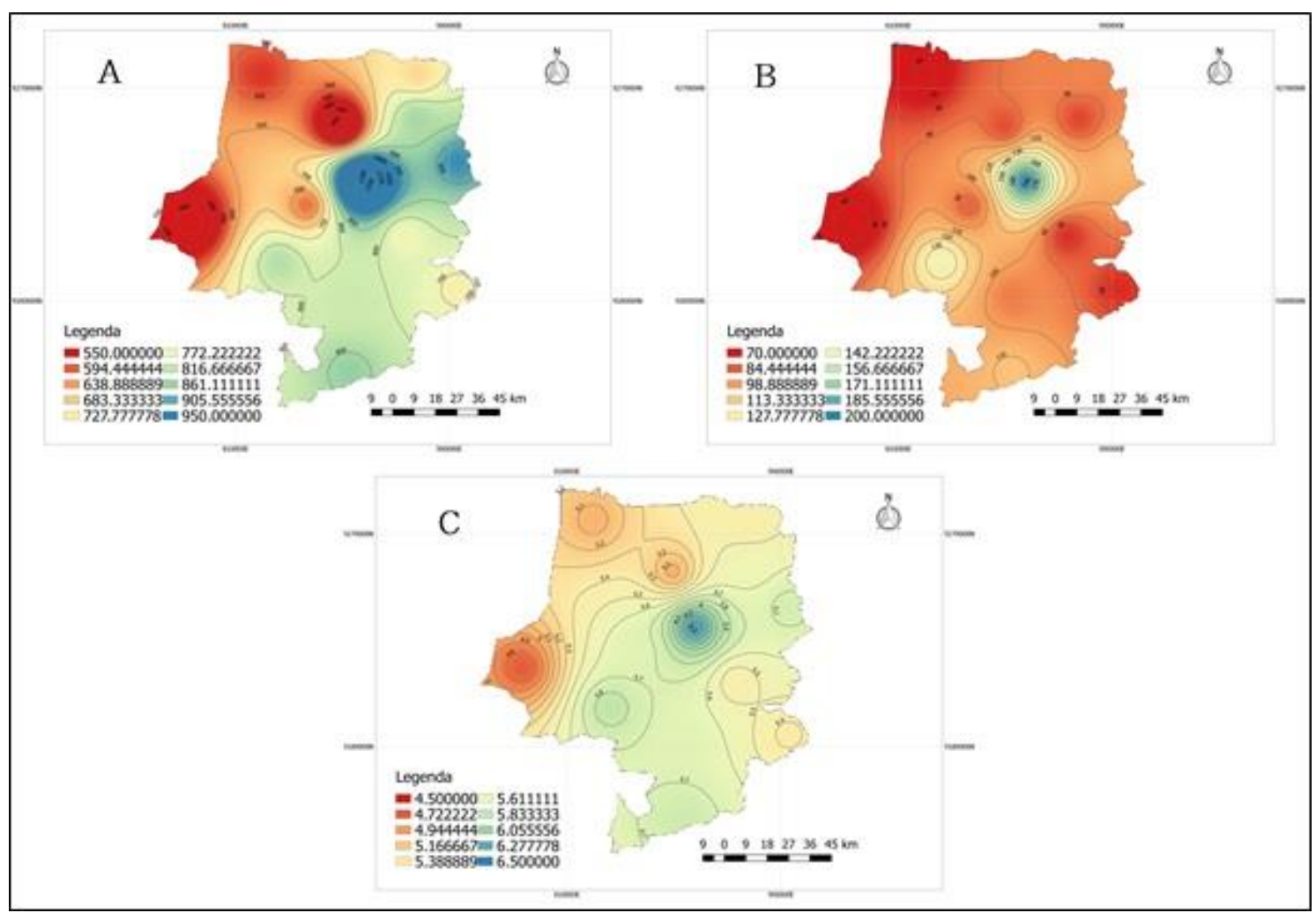

Figura 4. Mapa de distribuição e de isolinhas da precipitação média anual (A), do número de dias chuvosos (B) e da entropia média anual (C) na mesorregião do Agreste, Paraíba.

O número de dias chuvosos (Figura 4B), tem menor variação espacial que a precipitação na mesorregião do Agreste, diferindo das demais microrregiões apenas o Brejo, que possui o maior número de dias chuvosos (130 a 190 dias), e a microrregião de Campina Grande (100 a 130 dias). Na maior parte do Agreste o número de dias com chuvas varia entre 60 e 100 dias.

A entropia (Figura 4C), na mesorregião do Agreste é mais alta no Brejo, com valores entre 5,7 e 6 bits, corroborando com a precipitação e o número de dias chuvosos, sendo essa a microrregião de maiores precipitações e melhor distribuição no tempo. A entropia no Agreste teve menores valores no Curimataú Ocidental (4,8 a 5,5 bits) e Oriental (5,1 a 5,3 bits), nas demais microrregiões (Campina Grande, Esperança, Itabaiana, Umbuzeiro e Guarabira) a entropia foi semelhante, variando entre 5,4 e 5,8 bits.

A precipitação na mesorregião da Borborema (Figura $5 \mathrm{~A}$ ), foi maior na microrregião do Cariri Ocidental, chegando aos $720 \mathrm{~mm}$ na cidade de Taperoá e 620 $\mathrm{mm}$ em Monteiro, nota-se que o regime de chuvas é bastante variável espacialmente. 
No Seridó Oriental e Cariri Oriental as menores precipitações foram registradas, com valores mínimos de 420 e $360 \mathrm{~mm}$, respectivamente, sendo essas as regiões com menores precipitações no estado. Mesmo havendo essa variação entre algumas localidades a precipitação para grande parte da mesorregião variou entre 460 e 560 $\mathrm{mm}$.

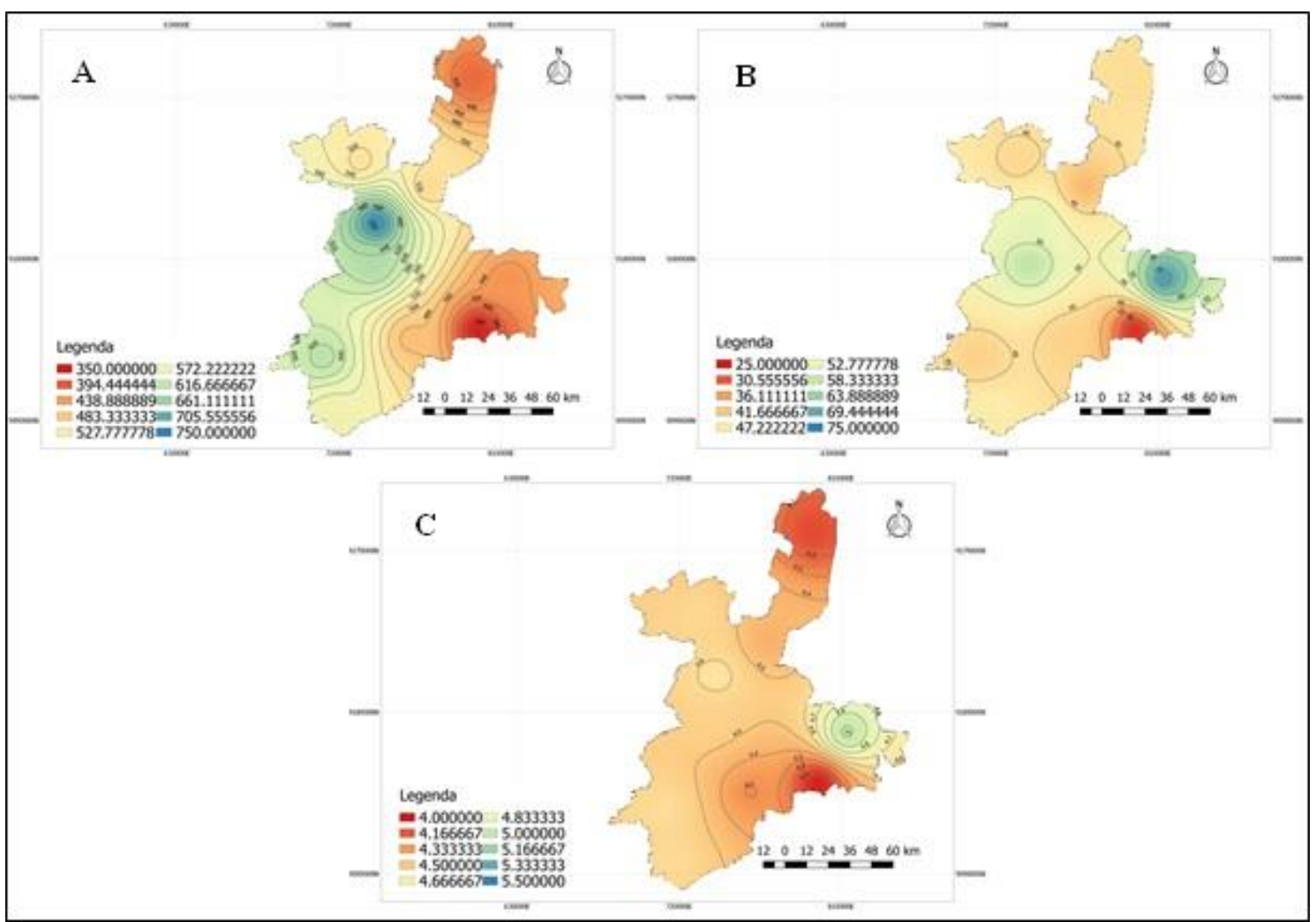

Figura 5. Mapa de distribuição e de isolinhas da precipitação média anual (A), do número de dias chuvosos (B) e da entropia média anual $(C)$ na mesorregião da Borborema, Paraíba.

Conforme possível observar na Figura 5B, o número de dias chuvosos variou pouco na mesorregião da Borborema, os valores variaram para boa parte da região entre 40 a 50 dias, divergindo das demais microrregiões apenas o Cariri Oriental, que apresentou os mínimos e máximos dias com chuvas, 30 e 70 dias, respectivamente nas cidades de Barra de São Miguel e Cabaceiras, mesmo a última cidade citada sendo considerada a que menos chove no país (SILVA et al., 2003), fato que diverge do que foi encontrado nesse trabalho, aonde a cidade de Barra de São Miguel (Figura $5 \mathrm{~A})$, apresentou dias chuvosos semelhantes a algumas localidades do Litoral. 
Conforme possível observar a distribuição da precipitação no Sertão (Figura $6 \mathrm{~A})$, as microrregiões de Cajazeiras, Sousa e Piancó é onde se encontram os maiores índices pluviométricos, respectivamente com máximas de 940, 880 e $880 \mathrm{~mm}$ anuais. Já as menores precipitações são distribuídas nas microrregiões de Teixeira, Itaporanga e Patos, com mínimas de 620, 700 e 720 mm, respectivamente. Para a maior parte do Sertão os valores variaram entre 780 e $840 \mathrm{~mm}$.

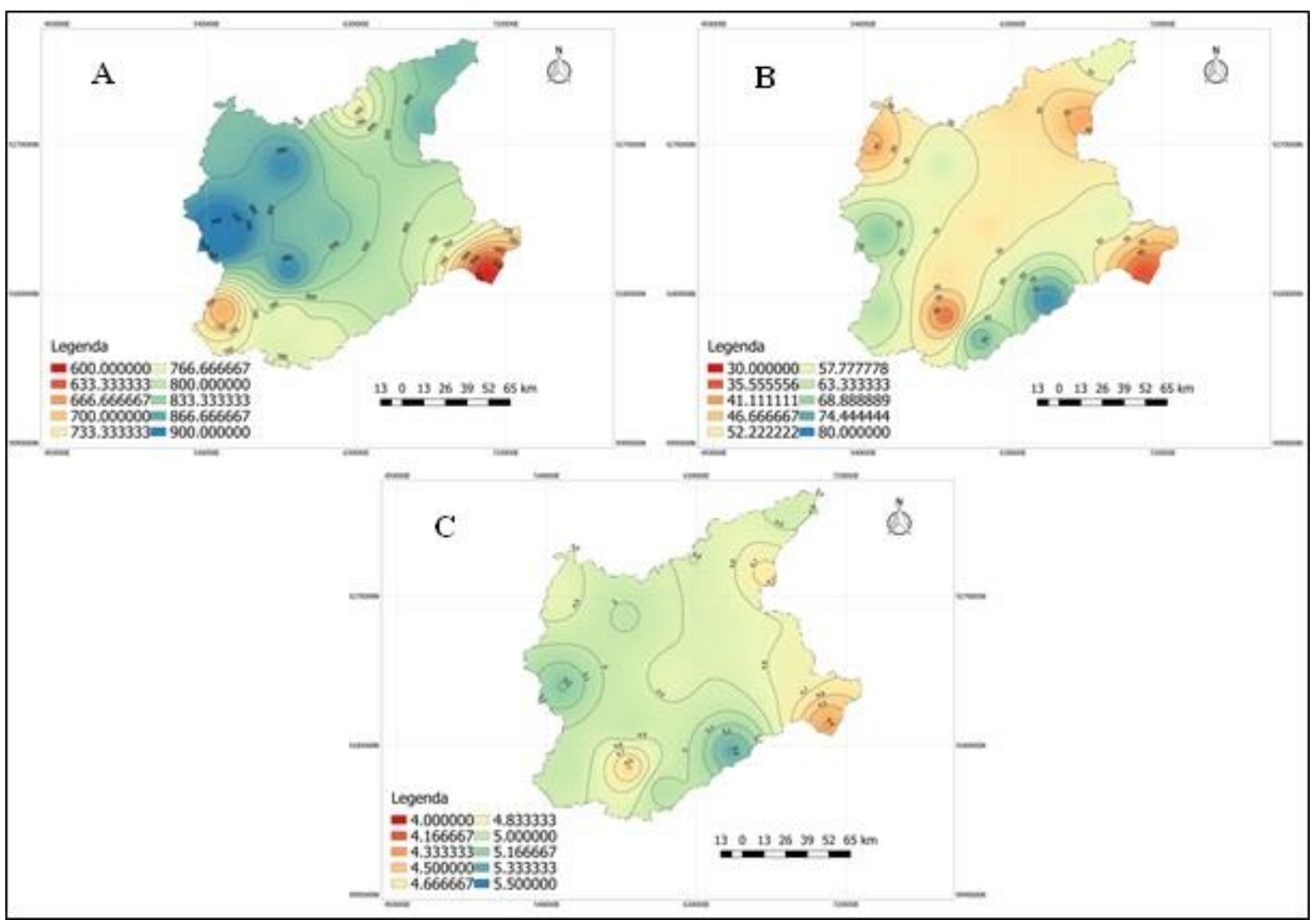

Figura 6. Mapa de distribuição e de isolinhas da precipitação média anual (A), do número de dias chuvosos (B) e da entropia média anual (C) na mesorregião do Sertão, Paraíba.

A microrregião da Serra do Teixeira foi a que apresentou maior variabilidade espacial no número de dias chuvosos (Figura $6 \mathrm{~B}$ ), onde os menores e maiores valores foram encontrados, respectivamente 40 e 75 dias, nas cidades de Desterro e Água Branca. Na maior parte do Sertão o número de dias com chuvas variou entre 45 e 55 dias, com pouca variação nas demais microrregiões que não sendo a Serra do Teixeira. A distribuição da entropia no Sertão (Figura 6C), foi mais similar ao número de dias chuvosos que a precipitação.

\section{DISCUSSÃO}


Os resultados da distribuição espacial da precipitação média anual no estado da Paraíba são semelhantes aos observados por Pereira et al. (2007), avaliando a variação anual e interanual da precipitação e do número de dias chuvosos nesse estado. Os valores de entropia foram semelhantes aos encontrados por Silva et al. (2003), avaliando a precipitação com base na teoria da entropia para a Paraíba, com uma série de 10 anos.

A entropia é máxima quando em todos os dias há registro de precipitação iguais entre si, dessa forma a entropia torna-se uma função logarítmica crescente em n, que aumenta de acordo com o número de dias da série (SILVA et al., 2003). Se tratando do período de um ano, em que $n$ é igual a 365, o valor máximo com o logaritmo na base 2 é próximo a 8,51 bits, e a variação temporal é zero. Dessa forma, as regiões em que a variação dos dados temporalmente apresentam-se menores são aquelas com maiores valores de entropia, representada no presente estudo pelas mesorregiões do Agreste e Mata paraibana. A mesorregião da Borborema por sua vez, apresentou a maior variação temporal da precipitação e o Sertão apresentou-se com uma variação intermediária.

O Brejo Paraibano destaca-se na mesorregião do Agreste pelos valores expressivos de precipitação, nessa região especificamente destacam-se as chuvas orográficas, as quais ocorrem por ação física do relevo, atuando como barreira à ascensão do ar causada pela advecção livre. Esse ar úmido e quente, ao ascender próximo às encostas, resfria-se adiabaticamente devido à descompressão causada pela maior densidade do ar nos níveis mais elevados, conduzindo a saturação do vapor, possibilitando a formação de nuvens e posterior precipitação. Dessa forma, as vertentes a barlavento são comumente mais chuvosas do que aquelas a sotavento, nesse caso as microrregiões de Esperança e o Curimataú, onde o ar, além de estar menos úmido, é forçado a descer, o que dificulta a formação de nuvens (MENDONÇA e DANNI-OLIVEIRA, 2007; VIANELLO e ALVES, 2012).

Para a mesorregião da Borborema, a entropia foi mais baixa em parte do Seridó Oriental e em parte do Cariri Oriental. Na maioria da Borborema, onde a entropia não variou muito, os valores ficaram entre 4,4 e 4,6 bits. O valor máximo da entropia na mesorregião foi de 5 bits no Cariri Oriental, mostrando que essa microrregião é a que mais apresenta variação espacial também para essa variável. Conforme Alves et al. 
(2015), a variação temporal e espacial da precipitação no Cariri Oriental se dá por influência das baixas altitudes e o relevo, caracterizando como uma região interplanáltica.

A distribuição da entropia no Sertão, mostra que a variabilidade temporal da precipitação nessa região depende mais do número de dias em que a chuva é distribuída do que o acumulado precipitado. Os valores dessa entropia para a maioria da mesorregião variaram entre 4,8 a 5,1 bits, valores esses superiores aos encontrados por Lêdo et al. (2012) na bacia do Alto Jaguaribe no Ceará, cujo os mesmos variaram entre 2,31 a 2,56 bits para a entropia anual, com isso verifica-se que mesmo nos locais de menores entropia na Paraíba a variação temporal da precipitação é menor que em outras localidades de estados vizinhos.

\section{CONCLUSÕES}

A técnica da entropia de Shannon como método de avaliação da variação da precipitação permitiu as seguintes conclusões: a entropia decresce no sentido da Mata paraibana e do Sertão para a Borborema, dessa forma a Borborema é a mesorregião de maior variabilidade temporal da precipitação; a variabilidade espacial da precipitação é bastante acentuada na Paraíba, sendo que é menor no Sertão do estado, exceto para a microrregião de Teixeira, parte de maior altitude na mesorregião, sendo interessante estudos futuros com a ligação do relevo e a variabilidade da precipitação; a variabilidade temporal da precipitação é maior em localidades com menor número de dias chuvosos e menor precipitação anual, dependendo não unicamente do total acumulado, tornando-se interessante estudos futuros que correlacionem as três variáveis; a entropia permitiu o estudo da variabilidade temporal da precipitação no estado da Paraíba.

\section{REFERÊNCIAS}

ALVES, T. L. B.; AZEVEDO, P. V.; FARIAS, A. A. Comportamento da precipitação pluvial e sua relação com o relevo nas microrregiões do Cariri Oriental e Ocidental do estado da Paraíba. Revista Brasileira de Geografia Física, v.8, n.6, p.1601-1614, 2015. 
CHEN, Y. C.; WEI, C.; YEH, H. C. Rainfall network design using kriging and entropy. Hydrol. Process., v.22, p.340-346, 2008.

FARCHE, A. C. S.; JURGENSEN, S. P.; ROSSI, P. G.; TAKAHASHI, A. C. M.; BORGHI-SILVA, A. Respiração lenta e profunda aumenta a modulação vaga em gestantes. Scientia Medica, v.27, n.4, p. 1-7, 2017.

FERNANDES, F. M.; LAPOLA, D. M.; CARVALHO, M. H.; NEREGATO, R.; ZUBEN, C. J. V. Curva de sobrevivência e estimativa de entropia em Lucilia cuprina (Diptera: Calliphoridae). Iheringia, Série Zoologia, v.93, n.3, p.319-324, 2003.

FRANCISCO, P. R. M.; MEDEIROS, R. M.; SANTOS, D.; MATOS, R. M. Classificação Climática de Köppen e Thornthwait para o Estado da Paraíba. Brasileira de Geografia Física, v.8, n.4, p.1006-1016, 2015.

GOMES, O. M.; SANTOS, C. A. C.; SOUZA, F. A.; PAIVA, W.; OLINDA, R. A. Análise comparativa da precipitação no Estado da Paraíba utilizando modelos de regressão polinomial. Revista Brasileira de Meteorologia, v.30, n.1, p.47-58, 2015.

\section{JULES, J. R. Aspectos ecológicos de Anopheles do subgênero Nyssorhynchus} (Diptera: Culicidae) no Município de Cachoeiras de Macacu, estado do Rio de Janeiro: área de Mata Atlântica receptiva e vulnerável para malária. 2017. 88 f. Dissertação (Mestrado em Medicina Tropical) - Fundação Oswaldo Cruz, Instituto Oswaldo Cruz, Rio de janeiro, RJ, 2017.

LÊDO, E. R. F.; ARRAES, F. D. D.; SILVA, M. G. Análises da precipitação na bacia do Alto Jaguaribe baseado na teoria da entropia. In: INOVAGRI International Meeting, 2012, Fortaleza. Anais..., Fortaleza: 2012.

MACEDO, M. J. H.; GUEDES, R. V. S.; SOUSA, F. A. S.; DANTAS, F. R. C. Análise do índice padronizado de precipitação para o Estado da Paraíba. Revista Ambiente e Água, v.5, n.1, p.204-214, 2010. 
MEDEIROS, R. M.; SILVA, V. P. R.; GOMES FILHO, M. F.; FRANCISCO, P. R. M. Aplicação da teoria da entropia no estudo da precipitação pluvial em Teresina-PI. Revista de Geografia (UFPE), v.32, n.2, p. 206-218, 2015.

MENDONÇA, F.; DANNI-OLIVEIRA, I. M. Climatologia: noções básicas e climas do Brasil. Oficina de Textos, São Paulo, 2007. 206 p.

PEREIRA, E. R. R.; SILVA, V. P. R.; BRAGA, R. C. estudo da variabilidade anual e intraanual da precipitação pluvial e do número de dias chuvosos no Estado da Paraíba. In: XV Congresso Brasileiro de Agrometeorologia, 2007, Aracaju. Anais..., 2007.

RODRIGUEZ, J. L. (Org.). Atlas Escolar da Paraíba. João Pessoa, ed. Grafset, 2002. $192 \mathrm{p}$.

SANTANA, L. V. R. Análise da variabilidade e similaridade da velocidade do vento no Nordeste do Brasil. 2018. 75 f. Tese (Doutorado em Biometria e Estatística Aplicada) - Universidade Federal Rural de Pernambuco, Recife, PE, 2018.

SHANNON, C. E. A mathematical theory of communication. The Bell System Technical Journal, v. 27, p. 379-343, 1948.

SILVA, V. P. R.; CAVALCANTI, E. P.; NASCIMENTO, M. G.; CAMPOS, J. H. B. C. Análises da precipitação pluvial no Estado da Paraíba com base na teoria da entropia. Revista Brasileira de Engenharia Agrícola e Ambiental, Campina Grande, v. 7, n. 2, p.269-274, 2003.

SILVA, V. P. R.; PEREIRA, E. R. R.; ALMEIDA, R. S. R. Estudo da variabilidade anual e intra-anual da precipitação na região Nordeste do Brasil. Revista Brasileira de Meteorologia, v.27, n.2, p.163-172, 2012.

VIANELLO, R. L.; ALVES, A. R. Meteorologia básica e aplicações. 2.ed. Viçosa, MG: Ed. UFV, 2012, 460 p. 